\title{
Features of Management Decisions by the Head of an Educational Institution, Their Assessment in the Conditions of Crisis
}

\author{
Marianna Shvardak \\ Mukachevo State University \\ Nazar Bozhynskyi \\ Kharkiv National University of Civil Engineering and Architecture \\ Bohdan Bozhynskyi \\ O.M. Beketov National University of Urban Economy in Kharkiv \\ Nataliya Kondratenko \\ State University of Telecommunications \\ Hanna Marchenko \\ State University of Telecommunications
}

The innovative and socio-economic preconditions of the state growth process make it urgent to develop education and modernise education management, to improve the competence of administrators at all levels and to model the mechanisms of human interaction, psychology and educational philosophy. The purpose of the study is to examine the characteristics and conditions of management decisions determined by the head of an educational institution, his competence to make and implement them in a crisis situation to achieve high results. An urgent need for management decisions may arise due to external or internal circumstances. It is a kind of response to indirect influences, which aims at solving a particular problem and getting as close to the goal as possible. The practical significance lies in finding the best methods and forms of managerial decision-making that will help the rational implementation of the educational process at school in crisis.

Keywords: management decisions, manager, general secondary education institutions, professional competence, educational objectives, crisis

\section{INTRODUCTION}

The management decision-making process is influenced by the pressures of many factors. The main factors are the degree of risk, the degree of support from the head of the team and the personal qualities of the head of the school. The degree of risk is related to the likelihood of making a rationally wrong decision and increased liability, which can adversely affect the institution. It exists when the manager has sufficient 
information to assess the possible consequences. The results of such decisions are not certain, but the probability of each is already known. The degree to which the supervisor is supported by the team implies understanding with subordinates, in the worst case a problem has to be solved by using personal qualities to facilitate the implementation of decisions. In terms of the personal qualities of a manager, they play a critical component in the implementation of management decisions. Indeed, experience, organisational skills, psychological characteristics and professional level form the basic image. Core competences are interpreted as intercultural and interdisciplinary skills, abilities and knowledge that are necessary for productive work and adaptation in different professional situations and environments.

At the present stage, according to scientific and technological progress, updated requirements for the level of managerial culture, competence and professional qualification of heads of educational institutions are proposed. The key tasks that contribute to their excellence and ensure professional fulfilment through educational reform are formed. Management creates the means to influence the subjects of the process, develops and improves the specifics of the institution to implement regional and national education sector development programmes to provide qualified management functions. Free orientation in contemporary cultural and information spaces with the continuous development of creative potential are considered to be universally recognisable components of free access to pan-European educational services and opportunities. The ability of the head of an educational institution to assimilate social and moral experience and to translate abstract possibility into ownership of professional status is one of the main factors of his personal development and directly influences managerial decision-making. It manifests itself in the self-affirmation process of the subject of managerial activity with elements of progressive consideration of regulation and orientation. The professional leader's decision-making structure is revealed through the acquired pedagogical skills, which together develop task-oriented actions in a coherent manner, especially in crisis situations.

The director of a general education institution should be clearly aware of the aspects of theoretical threats, his work and the teachers' level of pedagogical skills on which management decisions depend. Their implementation enables the manager to form his own system for assessing the situation in relation to the solution of a particular issue. An important factor is the choice of a rational path for the sake of which it must adequately assess the situation and identify current and future challenges to address the issue. Managerial decisions are made to ensure the quality of the educational institution and should be based on theoretically grounded methodologies and provisions for organising their preparation. First and foremost, they aim to use an effective modus operandi to obtain the desired result. The following functions can be implemented by management actions: coordination, planning, forecasting and organisation of decisionmaking and execution; motivation and activation of pedagogical activities; correction of the teaching and educational process; adjustment and regulation of the institution's work.

The head of an educational institution must clearly understand and fulfil the tasks of his activity as defined in the job description. A breach of process indicators from regulatory requirements, which can be detected at the point of internal control, indicates a problem that needs to be addressed through a management decision. The ability to direct managerial action towards effective problem solving is an objective necessity for the functioning of an educational institution. Thus, the key to this process is the personal and professional qualities of the manager, which establish optimal use of his skills and knowledge, which are implemented in the techniques of managerial activity. The techniques refer to the individual areas of management, provided by management decisions. If an educational institution is not proactive, this indicates a formal managerial style and may lead to a degree of managerial instability and a number of deviations from normative and directive requirements.

The purpose of the present study is to examine the characteristics and conditions of management decisions determined by the head of an educational institution, his competence to make and implement them in a crisis situation to achieve high results. 


\section{MATERIALS AND METHODS}

The theoretical and methodological basis of the study is provided by the following methods: axiological, cognitive, strategic and adaptive. The axiological approach refers to the main focus of educational management activities by constituting the principal as the highest level of leadership of the educational institution. This method introduces social, sectoral and governmental schemes of moral and legal safeguards for human performance under certain conditions. The established system of motives and value orientations that determine the external and internal potential and success of an executive is examined. Internal guidelines are defined as values in the profession, reflecting the means and representations of achieving managerial goals. An individual content area was created in its process to actualise the professional values of human resources management. Accordingly, the method under study forms a comprehensive and individualised system of professional development dynamics.

The cognitive paradigm has helped to discern the categories of skills and knowledge as a kind of transformation from information flows to the consolidation of a new professional skill. It explores these concepts as a major resource for providing effective and quality management outputs, permeating all stages of ensuring the competitiveness of an educational institution. The cognitive approach encourages managers to use sociological and psychological aspects more frequently to identify sources of management effectiveness. Its main provision is a mechanism for achieving high quality management decisions. An important condition for the practical use of such a methodology is the high level of objective and subjective components of professional activity in the position held. Since the implementation of the determinants within this paradigm chooses to focus on the systemic development of managers as a holistic foundation of experience, knowledge, skills and adaptive capacity.

The strategic research method enabled the separation and systematisation of concepts based on a combination of the social system theory of the educational institution and oriented on the functioning of the management subject. This made it possible to highlight the conditions for strategic management, which are different according to the nature of the environment and the subject matter. Through this method, information for management decision-making was analysed to determine the content and sequence of actions to change the structure of institutions by reducing the indicators of uncertainty in the situation. The purpose of this approach is to examine the organisational management system and streamline its processes to achieve a productive level of final outputs. The functioning of the management structure in the same internal or external environment develops differently and affects the success of management decision strategies.

The adaptive methodology is about reconciling the various influences on the education system in crisis. Its rationale facilitated an analysis of the theory of instability and explained non-linear development processes due to multifactorial influences. Such development of any formations occurs when a management system moves from one state to another, requiring mobility and flexibility in management decision-making by the heads of educational institutions. This approach makes the development of interactive interactions and partnerships between governance participants relevant, which is missing in times of crisis and uncertainty.

\section{RESULTS AND DISCUSSION}

A management decision is an organisational response to a particular problem, endorsed by choosing a specific course of action based on a perception of the goals, objectives, tools to achieve them and the choice of action in the prevailing conditions. It is closely linked to the management functions, serving each other and acting as a means of continuous influence of the subject on the object. The decision is a chain mechanism between the two subsystems and sets the parameters for management action by providing programmes of necessary actions. Programmes have specific procedures, standards and norms aimed at the following basic principles: efficiency, timeliness, optimality, specificity, feasibility. Based on these, management decisions need to be made to achieve results under the prevailing conditions. At the moment the means are used in favourable conditions, the sequence and modus operandi are determined. Therefore, 
the goal is concretised in the solution, which then moves to practical implementation based on knowledge of the circumstances, the modus operandi and the conditions. The diversity of tasks and objectives of management activities creates a diversity of types.

Management decisions are the result of the managerial activity of the institution and the deliberate intentions to achieve the management objective. Pedagogical management methods are translated into solutions by direct interaction, flowing from the controlling system to the managed system and making a concrete impact to ensure that the expected results are achieved. An effective management decision can be made by analysing certain problems and processes of educational activity from the perspective of the strategic motives and interests of the educational institution. To realise such tasks, the manager makes general arrangements and defines responsibilities between the team, which, in accordance with their job descriptions, may take these decisions when it is necessary to allocate management activities. This approach is appropriate in relation to general solutions. The specific nature of the management activities of educational institutions involves the constant implementation of binding decisions within the team, requires the subordination of certain functions and the constant alignment of actions with common goals. It is driven by many elements of technical means, information and people, so the balanced introduction of all the components of management gains efficiency and rationality from the holistic process.

In the current stage of development, the head of an educational institution has to work through a period of reorganisation of management activities and functional responsibilities related to the different conditions of the country's development and an increase in skills in the field of educational management. The subject of management influence needs to structure practical and scientific knowledge of management theory in a new way. Special communication skills help to shape the task clearly, deal with conflict situations and conduct business negotiations effectively. Professional culture is, therefore, an important factor in the management activity of the head of an educational institution. He tries to predict a certain outcome when evaluating decisions, but through a series of certain factors and external changes, sometimes this is not possible. Therefore, an important component in making a management decision is to determine the likelihood of its possible implementation in accordance with specific intentions. The chances of effective implementation are increased, when a certain number of employees of the educational institution are involved in the process of its adoption, and when the whole management process, including the organising and motivating functions, is put into action.

The modernisation of the education system primarily encourages a renewal of the management activities of the heads of institutions. The current context reveals the need to rebuild a competitive and personalised system. The supervisor is situated between pedagogical and socio-economic modifications, coordinating teachers to be able to make independent management decisions and successfully implement all strategic tasks. To effectively implement this process in the current context, a qualitative change in the mindset of the head of an educational institution is necessary. This transformation should be based on the theoretical training of pedagogical management, to plan a strategy for further development, to operate with new concepts, to see the future aspects of the institution. The refreshed mindset will unleash the stereotypes of the manager, help him feel a sense of absolute responsibility for managerial decision-making, express his individuality and focus on performance. The management is a driving component, aiming to motivate and energise by creating the optimum conditions for the implementation of management tasks in educational institutions. Therefore, it is important for managers to become familiar with modern management techniques and methods and to learn and use them successfully in their work.

The education system contributes to the implementation of the main objectives of the cultural and socioeconomic development of society. Providing a technological method encourages the developmental nature of all management activities. The main focus of the development of the domestic education system is to solve management problems and problems of personal development of the pupil and the technologisation of this process. In this paradigm, the supervisor performs the role of all types of managerial activities, whose professional skills are focused on diagnosing, controlling knowledge and developing students' skills. The pedagogical management technologies, as a set of rational and consistent execution techniques leading to the implementation of management decisions, in the management aspect assume the attainability of the goal through the intensification of changes in the process unit. The integration of control technology is due 
to the quality control function available. To achieve its process, it is necessary to combine the properties of an external management decision to focus on the quality of vocational education and training and to find modern approaches to the qualification of pedagogical management. Both subjective and objective influences have an impact on the relationship between decisions and pedagogical technologies.

The management of general education institutions is characterised by a complex management subsystem, due to the differentiated areas of work and the atypical characteristics of the school as an educational institution. The school has three levels of management: the principal, the deputy principal and the teachers. In this context, it is an indispensable task of the head of the institution to distribute management decisions evenly within the team, to create an optimal psychological space, and to increase the role of the school's management level. It is important to help workers recognise and realise their managerial roles. The management structure of an educational institution is characterised by a significant number of collegiate bodies, such as the school council, the scientific-methodological council, the attestation commission and the teachers' council, which also carry out management decisions within the institution. The manager needs to be clear about how to implement them and to engage as much as possible with collegiate bodies, since this is a big step from organisation to self-organisation and from management to self-management. Transforming the performance appraisal phase into an intensive self-development phase will ensure that the consequences of performance are effectively addressed in the management of the institution.

An educational institution acts as an open system influenced by different micro- and macroenvironments, the nature of which depends on the intensity of political and socio-economic factors influencing society, as well as on the interaction of the institution with its environment, which is dependent to changes. The challenges associated with the development of the existing system can be solved solely by an educational institution that deals with routine management issues on a day-to-day basis. Thus, in the case of a passive position of leadership, it is possible to assert a spontaneous relationship with the sphere of the environment. Thus, in the case of a passive position of leadership, it is possible to assert a spontaneous interaction with the environment. The destabilising components begin to intensify, preventing certain factors and information from being taken into account for effective management decision-making. Therefore, management activity is productive when the state ensures that the conditions are implemented as optimally as possible, and their regularity corresponds to the principle of unity between internal management instruments and state instruments.

An important principle of management decision-making is the rational combination of centralisation and decentralisation in the management of education systems. Centralisation blocks the initiative of lowerlevel managers and teachers, who become implementers of decisions made without their willingness or participation. In such an environment, there is duplication of management functions, overloading of managers and lack of time. Disapproval of centralization in the opposite direction can lead to a decrease in the role and authority of the leader, causing a loss of control and analytical functions in management. The synthesis of these concepts satisfies the interests of managers, creating the proper conditions for discussion and decision-making at a pedagogically professional level and ending the process of duplication by increasing the coordination of all structural subsystems. The focus of the process relies on the knowledge and experience of colleagues, organising the development and discussion of the best solution, without excluding the responsibility of the individual team member for the implementation of the assigned task.

When making management decisions, the head of the educational institution should take into account the risk factor, which refers to the level of certainty in predicting the outcome achieved. In assessing alternatives and making decisions, the head of the institution needs to predict their outcomes in a variety of circumstances in relation to risk. These circumstances can be classified as conditions of certainty, uncertainty and risk. In the context of certainty, a management decision is made by a manager when he knows precisely the outcome of each alternative. Solutions taken under conditions of risk are not certain, only the probability of a particular outcome is known. The manager should direct his actions towards finding options to mitigate the risk. In the context of uncertainty, decisions are made when it is not possible to evaluate the probable potential outcomes. Such a case can occur when the influencing factors are sufficiently complex or new that it is challenging to get clear data on them. Time and information 
frameworks also have a major impact on management decision-making, so they must be implemented during a period of accurate assumptions and information.

In the process of decision-making, certain changes may occur due to external or internal reasons, due to which there is a need for changes in the content of tasks, executors or deadlines. Therefore, their implementation should include a process for adjusting necessary changes, especially for decisions that are made under conditions of uncertainty or crisis. It should be noted that any changes in the implementation process should not create additional unforeseen problems for the implementers. The implementation of management decisions should end with a debriefing, regardless of the results. It is important to review all phases of the work to continue to achieve the objective and to meet the deadlines. The outcomes of a management decision are characterised by educational features, because the team and implementers need to understand the outputs that have been achieved. That is, in a way, gaining and improving experience in dealing with similar situations by processing the mistakes and achievements of the immediate process. It is possible to use new techniques and methods in the future, which can be of enormous benefit to management decision-making.

Awareness of the patterns of management decision-making in secondary education institutions allows for an assessment of the management system and in-depth analysis. Patterns improve the management process by taking into account the factors of the object under management, the development of the external environment, time, and establish a rational balance between subjective and objective components. The management system of the head of an institution is based on fundamental principles, reflecting its characteristic features. By principles we mean a starting point, created on sustainable patterns and trends in the development of a particular system. The management of educational institutions is aimed at ensuring and organising the optimum conditions for their functioning, creating a self-regulating mechanism and implementing the right for education. A decisive aspect in the organisation of management activities lies in ensuring and supporting close cooperation between the manager and the public administration and social organisations to create a comprehensive management system for the institution. The principles of democracy, humanism, science, differentiation of forms and contents of education are characteristic of managerial decision-making.

Management decision-making is usually divided into certain stages. The first stage stems from the examination, diagnosis and analysis of the specific situation identified. The necessary information about the status of the problem is accumulated and the causes that led to the problem are identified. The systemisation is carried out indirectly by the administration of the educational institution based on internal control. Insufficient information can lead a manager to make an ineffective management decision. Therefore, the information received should contain accurate facts, meet modern requirements, be understandable and have an informative and visual presentation. The second stage is characterised by decision-making, i.e., the evaluation and development of alternative management decisions are formed and the tasks for adopting the best possible version of the conditions for their implementation are determined. It is a consequence of choosing courses of action among the many suggested ones. The third stage represents the monitoring of the implementation of management decisions. For this reason, the effective outcome of the whole institution depends on the ability to follow the sequence of entities' actions and to approve the right decisions. The reviewing process acts as a complex management activity.

There are appropriate requirements for making and implementing management decisions in general secondary education institutions. First of all, they should have a scientific-theoretical basis, a logical sequence of implementation, not contradict the current legal and regulatory framework for the operation of the educational institution, and a clear delineation of existing problems. At the time of making the decision, the manager should take into account all proposals made by the employees of the institution, the possibility of financial and material costs, and the pedagogical and psychological conditions of the team at the stage of possible solutions to the problems. They should aim to address educationally relevant and fundamentally challenging issues. Management decision-making can be carried out in an authoritarian or group manner. The authoritarian method causes decisions to be made solely by the school principal, who relies on his own experience, vision and ideas, trying to determine how to implement them on his own. The group approach provides an opportunity for each member of the team or group to take his own initiative. This method 
involves the director engaging employees in making and effectively implementing management decisions by understanding and listening to each other.

To participate effectively in developing and making decisions, the head of an educational institution needs to understand the specifics of the systems approach and the division of functional responsibilities between himself and the professionals working on the tasks. It considers a set of objectives, participates in the risk assessment, assists in setting objectives, and monitors the timely preparation of the decision. Management decisions embody the mechanism of clear discipline and organisation practically necessary in the functioning of educational institutions. The decision acts as a directive act, coordinating, guiding and motivating collective activity as a whole. Its main impact refers to the socio-economic interrelationships and processes that are created in the teaching team. The success of implementation activities is determined by rational preparation and effective management decision-making. Solutions, in turn, are multidimensional and have characteristic legal, organisational, psychological and pedagogical components. It must have its mission, purpose, timeliness, comprehensiveness, legitimacy and be formalised.

The performance and quality of a management decision is determined by an analysis of the methodology for solving the principles and problems. The analysis of management theory and practice establishes the need for certain approaches, depending on the specific situation. For example: comprehensive, systemic, normative, procedural, behavioural, situational, administrative. These approaches should be used for all tasks, as adherence to them is an important factor affecting the quality of management decision-making. Their reasoning is characterised by a scientific feature that takes into account elements of the conditions associated with the use of qualitative information and problem solving. The core concept highlights such elements, as they require the special attention of the head of the educational institution and are crucial in their significance. Its optimality notes the ratio of expected and achieved results, taking into account the necessary costs of development and implementation. Consistency requires prior recommendation, taken together with decisions on the legal framework. The process of implementation actually compares the results achieved with the parameters previously set to identify significant changes and correct specific actions.

The implementation of management decisions by the head of a general secondary education institution serves as the main criterion for managerial activity and represents an algorithm of step-by-step work to achieve effective results. He serves as a certain tool for influencing subordinates and acts as a direct link between the head of the institution and the employees. The decision initiates the parameters of action and ensures the integrity and complexity of the programme, which, in turn, may take the form of instructions or rules that are the central subject of management. The most common types of such solutions are orders, meetings, pedagogical councils with training elements, discussions and festivals. These forms combine leaders, teachers, pupils and parents to create the conditions for teaching excellence, to inspire creative cooperation and to defend their positions freely. They achieve their goal when the team environment is optimal for productive work and even risky decisions in a crisis lead to a productive outcome.

The assessment of management decision-making by the head of a general secondary education institution is carried out on a systematic basis, involving a consistent analysis of the pedagogical and social conditions for improving management and identifying the conditioned parameters and components that embody a particular pedagogical condition. To systematise and calculate the assessment, modern computer technology is used to determine the elements of each condition and then scale it up. Performance appraisal is determined by work style and organisational talent, based on the results of personal contributions to the work process. The programme ensures that management decisions and the activities of the education and training institution as a whole are evaluated objectively. The level of managerial decision-making largely determines the success of the whole team. For this reason, its assessment criteria are an important benchmark for improving pedagogical excellence and a means of improving the quality of the institution, providing new ways to refine areas of activity. Indeed, the director is responsible for the economic, financial, educational and physical development of the institution towards the state.

One of the main ways of evaluating management decision-making in a crisis is monitoring, which improves the integrated management system of a general secondary education institution. The monitoring process is not possible without a clear organisation of the core processes of the system. It should be flexible 
and adaptive, encompassing different levels of management of the educational institution to adapt and quality levels of management and self-organisation. This system is based on tracking the institution's performance in specific areas, such as: creating conditions for education, preserving health and property by common assessments, and managing the institution effectively. In forming the overall assessment of each individual area, performance and capacity levels are taken into account. The assessment is based on selected specific indicators that were taken as a basis for monitoring and have been developed over the years in educational institutions. The head of the institution analyses the results of the monitoring studies in different settings and takes appropriate measures to develop and improve management activities. An organised monitoring system, therefore, has a positive impact on the productivity of management decision-making by the manager and his organisational units.

\section{CONCLUSIONS}

Thus, management decisions in educational institutions are the main components of management activity aimed at solving certain educational tasks and problems by determining the most effective algorithm of actions to implement the established objectives. The analysis of scientific, pedagogical, organisational, methodological and archival materials demonstrates the continuous process of renewal and development of the functions of the head of an educational institution. The main components of the conditional development of management activities are changes in the social system of the educational paradigm, the particularities and nature of management functions and changes in the socio-economic situation of the country. The basic element of managerial decision-making by the head of an institution is his professional competence, which manifests itself as a dynamic personal-professional phenomenon, provides professional organization of managerial activity in scientific-pedagogical requirements. The research process in an educational institution is a fairly complex process that requires professional knowledge and skills on the part of the head of the institution.

The effectiveness of the educational process depends on the promptness and quality of management decisions, as well as the ability of the head of the educational institution to identify modern management methods in a timely manner. The main components of management are regularities and trends related to the principles of educational supervisors. The social, pedagogical and economic processes determine the development of the functioning of educational activities. The education system reflects all phenomena that take place in the state, so the management of this system is the main driving force that aims to activate the optimum conditions for human development. Consequently, managers of educational institutions need to navigate the diversity of management decisions and successfully apply pedagogical experience and science to organise optimal management activities. In practice, the chances of effective implementation are greatly increased when the people involved have contributed to the solution and genuinely believe in what they are doing. Thus, a good way to gain acceptance of a management decision lies in involving other people in the decision-making process.

The managerial decision-making process lies at the heart of the effective operation of any educational institution. Hence, exploring these concepts is an integral part of contemporary scientific thought. The practice shows that management often neglects the consistency and rationality of their adoption. The result of this process is incompetence, which can threaten to identify a problematic situation, choose an ineffective way and method of implementing a solution, and form impractical goals. Thus, to improve the effectiveness of educational institutions, particular attention should be paid to the step-by-step reasoning process of preparing and making management decisions. After all, modern society needs independent and competent leaders in educational administration. In the proper organisation of management decision-making lies the foundation for the retention and effective use of information. Rational forms and methods of creating and processing decisions can only be brought to a common norm once everyone involved in the processes of creating and processing them, by following common norms, rules and regulations. 


\section{REFERENCES}

Anikin, I.Y. (2020). The use of technological cycles in the management of an educational institution by integrating marketing technologies. International Journal of Learning and Change, 12(1), 25-43.

Barber, M., \& Murshed, M. (2018). How to achieve a consistently high quality of teaching in schools. In Lessons from the Analysis of the Best School Education Systems in the World: Education Issues. London: Routledge.

Brim, O.G. (2020). Sociology and the field of education. New York: Rassel Sage.

Clausen, J.A. (2019). The life course of individuals. The sociology of age stratification. New York: Rassel Sage.

Connel, W.F. (2018). History of education in the 20-th century world. Canberra: Cyrriculum Development Centre.

Derlow, D. (2018). Key management decisions. Decision making technology. Scientific Opinion, 18(2), $12-19$.

Dirlav, D. (2018). Selected business-school concept. The theories that changed the world. New Jersey: Olimp Business.

Fishman, L.I. (2019). Modern director: Professional values and stereotypes. Berlin: DOM publishers. Gould, R. (2019). Transformation: Growth and change in adult life. New York: Simon and Schaster. Greiner, L.E. (2018). Patterns of organization change. Harvard Business Review, 54, 98-106.

Kin, T.M., \& Kareem, O.A. (2020). The relationship between emotional intelligence of school principals in managing change and deputy principal change beliefs. International Journal of Learning and Change, 12(2), 124-142.

Kleiner, J.S. (2019). Decision making: Models and systems. Berlin: DOM publishers.

Kosov, B.B. (2018). Typological features of activity style managers of different efficiency. Tallin: Tallinn Book Printers.

Kushnir, I.I. (2020). Modern view on educational management. Scientific Bulletin of Mukachevo State University. Series "Pedagogy and Psychology", 1(11), 28-31.

Mead, G.H. (2018). Mind, self and society. From the standpoint of social behaviorist. Chicago: Chicago University Press.

Ovdiuk, O. (2020). Formation technologies of the economic mechanism of management decision making. Scientific Horizons, 8(93), 65-71.

Rogers, C. (2020). Freedom to learn for 80s. Toronto: Ch. Merril Publ.

Shvardak, M. (2018). Modern technologies of management of educational establishments. International Scientific Journal "Education and Science”, 24(1), 227-230.

Shvardak, M.V. (2020). Modern methodological approaches to the formation of readiness of future heads of educational institutions to apply the technologies of pedagogical management. Bulletin of Taras Shevchenko Lviv National University, 5(336), 184-195.

Shvardak, M.V. (2020). Modern technologies of management of pedagogical staff in general secondary education. In Scientific achievements of modern society: Abstracts of the 6th International scientific and practical conference (pp. 1352-1359). Liverpool: Cognum Publishing House.

Stubler, E. (2019). Founders. Innovators in education. Edmonton: University of Alberta Press.

Sych, T.V., Kryvtsova, O.M., Kaduk, N.I., Nesprava, M.V., \& Panchenko, G.O. (2021). Public administration in the education system: Theoretical and methodological approaches and practical recommendations. Journal of the National Academy of Legal Sciences of Ukraine, 28(2), 132139.

Vasylenko, V.A. (2018). Theory and practice of development of management decisions. Kyiv: Vyshcha shkola.

Williams, R.B. (2020). Leadership for school reform: Do principal decision making styles reflect a collaborative approach. Canadian Journal of Educational Administration and Policy, pp. 118125. Canberra. 